\title{
Que bom te ver viva: vozes femininas reivindicando uma outra história
}

\author{
Kátia da Costa Bezerra ${ }^{1}$
}

\begin{abstract}
Não pode haver esperança verdadeira naqueles que tentam fazer do futuro a pura repetição de seu presente nem naqueles que veem o futuro como algo predeterminado. Têm ambos uma noção domesticada da História.
\end{abstract}

Paulo Freire

Em 1964, o Brasil foi sacudido por um golpe militar. O regime militar que se estendeu por 21 anos teve como premissa básica a Doutrina da Segurança, que compreendia dois pilares complementares: a segurança nacional e o desenvolvimento econômico (Stepan, 1976, p. 55). Para poder implementar as políticas necessárias, tornou-se indispensável suspender direitos civis e políticos. Os críticos ao regime militar foram presos, torturados, assassinados, sequestrados ou forçados ao exílio. O retorno ao regime democrático foi marcado pela presença de discursos que defendiam a necessidade de garantir uma transição conciliatória. Desde então, o que se verifica é a forma como certos grupos procuram monopolizar os discursos na esfera pública, dificultando o afloramento de outras falas que poderiam concorrer para uma reflexão mais profunda e plural do período da ditadura militar no Brasil. Soma-se a isso o fato de que, apesar da pressão por parte de diversos movimentos sociais e instituições, bem como dos familiares dos desaparecidos, as várias tentativas de resgatar a memória desse período têm se mostrado muitas vezes infrutíferas.

Mais recentemente, o debate em torno da memória da ditadura militar brasileira ganha novas proporções com a criação da Comissão Nacional da Verdade, que tem como finalidade apurar os casos graves de violação dos direitos humanos entre 1946 e $1988 .^{2}$ A comissão foi

\footnotetext{
${ }^{1}$ Professora no Department of Spanish and Portuguese da University of Arizona, Tucson, Arizona, Estados Unidos. E-mail: kbezerra@email.arizona.edu

${ }^{2}$ Inicialmente, o objetivo da comissão era enfocar especificamente o período da ditadura militar, mas a pressão por parte dos militares fez com que as datas fossem modificadas para descaracterizar a ênfase nos abusos perpretados pelo regime instaurado em 1964. Para mais sobre essa questão, ver Dias (2013).
} 
criada com o objetivo de abrir um espaço de discussão na busca da verdade em nível jurídico e pessoal. Constituída por sete membros dos mais diversos setores da sociedade, a comissão mesmo antes de sua criação foi alvo de constantes questionamentos, fosse por parte dos militares ou de grupos que exigem a punição exemplar dos torturadores. Desde sua implementação, arquivos foram abertos, e cerca de 350 pessoas foram ouvidas. Dentre estas, destacam-se mulheres que detalham seu papel na luta de resistência e a tortura física e psicológica a que foram submetidas.

Este ensaio examina a forma como a narrativa produzida por mulheres procura dar significado a experiências até então silenciadas. Pretende-se analisar o modo como esse rememorar se estrutura através da inter-relação entre a memória histórica e a memória pessoal, presente e passado. Tendo como ponto de partida o filme Que bom te ver viva (1989), de Lúcia Murat, o artigo discute o modo como o filme permite problematizar perspectivas que tentam fixar e restringir as possibilidades de leitura sobre o período da ditadura militar. Em outras palavras, o ensaio discute o modo como o filme constrói quadros da memória que vão além daqueles tidos como representativos - uma dinâmica que propicia o questionamento de uma sintaxe que perpetua a noção domesticada de história de que fala Paulo Freire. É sob essa ótica que se pretende examinar Que bom te ver viva.

\section{Um retorno no tempo}

O tenso debate em torno da memória desse período pode ser mais bem compreendido quando temos em mente que a memória coletiva funciona como um quadro social constituído a partir de fatos, valores e crenças que servem de ponto de referência para os indivíduos e a sociedade como um todo. Não se pode esquecer que a invenção da tradição está intimamente ligada à tentativa de impor uma política particular de seleção e organização que procura afirmar-se como representativa de toda uma comunidade (Hobsbawm, 1994). Trata-se de um processo de construção que exclui trajetórias ou perspectivas diferentes daquelas reconhecidas como representativas. Não é por acaso que estudiosos como Halbwachs argumentem que:

O que faz com que as memórias recentes se mantenham unidas não é que elas sejam contínuas no tempo: é mais que elas sejam 
parte de uma totalidade de pensamentos comuns a um grupo [...] Para relembrá-las é então suficiente que nos coloquemos a partir da perspectiva desse grupo, que adotemos seus interesses e sigamos o curso de suas reflexões (Halbwachs, 1992, p. 52-52, tradução nossa).

Por outro lado, a percepção da memória como uma atividade interativa e social nos obriga a reconhecer que todo ato de rememorar implica um processo de recriação, reelaboração, ressignificação do passado tendo o momento presente como referência. Isso ocorre porque “as imagens do passado não são ditadas pelo passado, nem totalmente inventadas no presente, mas resultam de um contínuo diálogo em que as imagens anteriores moldam e restringem o que pode ser feito com elas nos presentes sucessivos" (Olick, 1998, p. 552, tradução nossa). Isso implica dizer que o embate pelo direito de definir os parâmetros de reconstrução do passado se origina da coexistência de uma pluralidade de quadros sociais da memória, tendo em vista as diversas agendas políticas, econômicas e ideológicas dos mais diferentes grupos.

$\mathrm{O}$ embate em torno da memória, no entanto, ganha novos significados quando se trazem para o campo de disputa as vozes/perspectivas das mulheres. Não se pode esquecer que, para a mulher, revisitar o passado significa a narração de experiências "saídas de uma paisagem histórica sombria" (Haaken, 1998, p. 1). Em muitos casos, o resgate do passado implica uma forma de olhar que se esforça por captar elementos tradicionalmente trivializados. Nesse contexto, a ênfase no cotidiano funciona como uma estratégia que lhes permite problematizar o tom celebratório e excludente dos discursos oficiais. Ademais, quando se pensa no projeto da nação, deve-se ter em mente que:

Uma das principais dimensões dos projetos nacionalistas a ser relacionada com as relações de gênero [...] é a dimensão genealógica que é construída em torno da origem específica das pessoas (ou de suas raças) (Volknation). O mito de uma origem comum ou do compartilhamento de sangue/genes tende a construir as visões mais excludentes/homogêneas da "nação". Outra dimensão importante dos projetos nacionalistas é a dimensão cultural na qual a herança simbólica da linguagem e/ou religião e/ou costumes e tradições é construída como a "essência" da "nação" (Kulturnation) (Yuval-Davis, 1997, p. 21, tradução nossa). 
Essa dinâmica nos ajuda a compreender a restrição da mulher ao papel simbólico de "repositório conservador do arcaico nacional", o que implica seu alijamento, em nível simbólico, do processo de construção e transformação da nação, que passa a ser percebido como uma prerrogativa eminentemente masculina (McClintock, 1997, p. 93, tradução nossa). Essa percepção aponta para o caráter gendrado da narrativa da nação, uma vez que o papel das mulheres fica restrito à esfera da reprodução biológica, cultural e simbólica.

Essa faceta ganha uma dimensão mais conservadora durante regimes autoritários, quando a imagem da mulher fica ainda mais atrelada aos papéis tradicionais. Não se pode esquecer que uma das justificativas para o golpe militar foi a necessidade de defender os valores familiares ante a ameaça comunista. De fato, um dos vetores que marcaram a orientação ideológica do regime militar foi sua autocaracterização como uma instituição guiada por princípios católicos e familiares. Quanto aos movimentos de resistência ao regime militar, no início a ação ficou mais restrita às manifestações públicas e ao setor da cultura, todavia, a partir de 1968, e mormente com a implementação do AI-5, muitos desses jovens decidiram ingressar na luta armada. A resposta imediata do governo veio na forma de prisões, torturas, sequestros, exílios e desaparecimentos. A partir desse momento, esses jovens passaram a vivenciar uma prática repressiva que tinha como constantes as experiências da tortura, do isolamento e da falta de perspectiva, num mundo em que preponderava o absurdo e a falta de leis e de ética (Baffa, 1989).

Cumpre ressaltar que essa prática repressiva funcionou como uma peça chave para o regime militar, uma vez que lhe permitiu impor a submissão, a fuga, a segregação ou a eliminação de qualquer indivíduo que tentasse resistir ao seu discurso totalizador. As torturas eram conduzidas mediante agressão física e pressão psicológica. Segundo Hélio Pelegrino, "a tortura busca, à custa do sofrimento corporal insuportável, introduzir uma cunha que leve à cisão entre corpo e mente. E, mais do que isto: ela procura, a todo preço, semear a discórdia e a guerra entre o corpo e a mente. Na tortura, o corpo volta-se contra nós, exigindo que falemos" (Pelegrino apud Arquidiocese de São Paulo, 1985 , p. 281-282). Isso significa dizer que a tortura introduz um elemento cruel, que é a experiência de uma situação-limite que culmina num processo de desumanização do torturado quando este, em função 
da dor e da degradação, estabelece uma relação com o torturador, que o faz trair sua ideologia, suas crenças, seus companheiros.

No que diz respeito à luta armada, dados do próprio regime militar informam que a maioria dos militantes envolvidos nos movimentos de esquerda eram jovens estudantes oriundos da classe média, sendo que muitos deles eram mulheres (Arquidiocese de São Paulo, 1985, p. 85-86). Apesar dessa presença significativa de mulheres nos movimentos de resistência, na maioria das vezes a maior visibilidade é dada à experiência masculina. ${ }^{3}$ É essa prática que filmes como Que bom te ver viva, de Lúcia Murat, tentam colocar em questionamento. Lançado em 1989, o filme se estrutura a partir do contraponto que se estabelece entre o depoimento de oitos ex-prisioneiras políticas, fotografias, reportagens dos jornais da época e o monólogo de Irene Ravache, que, ao interpretar uma ex-prisioneira política, interpela o público. A proposta do filme fica clara logo no início, quando a personagem de Ravache, sentada no chão em frente a um aparelho de televisão enquanto troca um vídeo, afirma: "Vejo e revejo as entrevistas e a pergunta permanece sem resposta. Talvez o que eu não consiga admitir é que tudo começa aqui, na falta de respostas. Acho que devia trocar a pergunta. Em vez de 'Por que sobrevivemos?', seria 'Como sobrevivemos?'”.

Essa mudança em perspectiva nos ajuda a entender por que, embora a questão da tortura seja uma constante na fala das ex-prisioneiras políticas, a ênfase é dada mais à forma como elas vivenciaram ou tentam superar as sequelas da tortura do que propriamente às técnicas de tortura. Da mesma forma, há uma preocupação em marcar a diversidade de vivência dessas mulheres. Por esse motivo, antes de dar a palavra a cada uma das ex-prisioneiras políticas, o filme as apresenta ao público. Num primeiro momento, o público assiste a um pequeno trecho do depoimento dessas mulheres para, no quadro seguinte, ver a imagem das grades de uma prisão em que se pode visualizar o retrato da ex-prisioneira e alguns dados sobre cada uma delas: nome completo, o grupo de resistência ao qual pertencia, o período em que esteve presa e foi torturada e, finalmente, dados mais recentes como profissão, filhos, estado civil. Neste como em outros momentos ao longo do filme, observa-se a mesma dinâmica: as cenas que se reportam ao passado são

\footnotetext{
${ }^{3}$ Pode-se citar o caso de filmes como Pra frente, Brasil (Roberto Farias,1982), Lamarca (Sérgio Rezende, 1994) e O que é isso, companheiro?(Bruno Barreto, 1997), por exemplo.
} 
em preto e branco, contribuindo para a criação de uma estética que marca um momento de opressão e violência.

A fala das ex-prisioneiras, no entanto, não é marcada só pela diversidade, mas principalmente pela tentativa de "relatar histórias incomuns de pessoas comuns", como adverte Jessie Jane. Vários são os temas abordados durante as entrevistas. Em muitos momentos, elas se referem à dificuldade em encontrar um equilíbrio entre a impossibilidade de esquecer o passado e a necessidade de continuar vivendo. Maria do Carmo Brito, por exemplo, recorda o pacto de morte que tinha com o marido e o sentimento de culpa que a perseguiu por muitos anos por não ter tido coragem de tirar sua própria vida. No caso de Regina Toscano, sempre preponderou o medo de ter um ataque epiléptico durante as sessões de tortura, pois ela sabia que os torturadores se aproveitariam de sua convulsão para degradá-la ainda mais. Rosalina Santa Cruz, por sua vez, traz a questão dos desaparecidos ao se reportar ao irmão, afirmando veementemente que a figura do desaparecido foi a invenção mais cruel da ditadura porque, com "um morto sem corpo, não há o sentimento de morte". Por essa razão, por muitos anos ela se sentia culpa quando estava se divertindo com os amigos. Se algo parece interligar a experiência dessas mulheres, no entanto, é o sentimento de perplexidade ante uma realidade que não conseguem compreender. Ao contrário do que se poderia pensar num primeiro instante, seu rememorar não é marcado só pela dor, uma vez que a gravidez é percebida como uma forma de resistência à violência, ou mesmo uma certeza de que a vida continua. ${ }^{4}$

Todavia o depoimento de duas mulheres em especial chama a atenção pela forma como elas lançam um olhar crítico sobre a atuação dos grupos de esquerda a que pertenciam. O primeiro caso é o da exprisoneira política que prefere ficar anônima. A audiência só tem acesso a uma carta escrita por ela e ao depoimento de uma pessoa que costumava visitá-la enquanto esteve presa. Vivendo numa comunidade mística, a ex-prisioneira fala da necessidade de encontrar um equilíbrio emocional para que se possa construir algo positivo. Na carta, ela deixa claro que "não existem moços e bandidos" e, sem aceitar o papel de vítima, atribui a violência aos dois grupos. Através do depoimento da

\footnotetext{
${ }^{4}$ A exceção aqui seria o caso da mulher que pede para ficar anônima. Nós não temos nenhuma informação no que diz respeito a filhos.
} 
pessoa conhecida, ficamos sabendo que ela foi cruelmente torturada a ponto de se desestruturar e passar dados para os torturadores, o que resultou na sua expulsão da organização de esquerda de que fazia parte. Algo muito parecido aparece no depoimento de Maria Luiza G. Rosa. Presa quatro vezes durante os anos 70, ela fala de sua ingenuidade em acreditar que poderia mudar o mundo. Com o rosto tenso e evitando olhar diretamente para a câmera, ela descreve a forma como ela foi se desestruturando nas várias sessões de tortura até o momento em que começou a passar informação para os torturadores. Censurada por sua postura, ela relembra a dificuldade de falar sobre a tortura com os próprios companheiros de cela. ${ }^{5}$

O que se pode detectar nesses diferentes depoimentos é a forma como o filme procura se distanciar de uma série de discursos que procuram legitimar uma memória totalizadora que tem sido tradicionalmente articulada a partir de binarismos: heróis vs. terroristas, vítimas vs. algozes. Trata-se de um processo de construção da memória que, marcada por uma linguagem "militarizada", promove uma postura "não reflexiva e que exclui a possibilidade de perguntar questões sobre a natureza da experiência" (Avelar, 2004, p. 65, tradução nossa). Que bom te ver viva foge dessa dinâmica ao trazer a dimensão do sofrimento, as tensões internas bem como os momentos de perplexidade, fraqueza, alegria e revolta na tentativa de rearticular novas leituras sobre esse período da história do país. Essa estratégia também se faz presente na forma como o filme intercala reportagens de jornais da época sobre a ação dos movimentos de esquerda com os depoimentos emocionados das ex-prisioneiras e, em alguns casos, com fotografias que registram cenas "triviais" do passado. No caso de Maria do Carmo Brito, as fotos se reportam a uma festa em família e ao convívio com o filho pequeno. As fotos de Criméia de Almeida e Jessie Jane recapturam a alegria no convívio com os filhos nascidos na prisão. Em suma, as fotografias tentam recuperar uma dimensão do dia a dia ausente dos relatos oficiais e que permite construir uma imagem com a qual a audiência pode se relacionar. Mais do que isso, ao trazer a dimensão humana como parte constitutiva dos relatos das ex-prisioneiras, o filme problematiza a

\footnotetext{
${ }^{5}$ Uma questão, no entanto, que não se restringe ao passado uma vez que muitas delas se referem à forma como amigos e familiares reagem quando elas abordam o assunto da tortura. A sensação que elas descrevem é de uma obrigatoriedade de se calar e esquecer.
} 
forma mitificada como os militantes têm sido tradicionalmente representados.

Esse processo de reescrita da memória se consubstancializa, portanto, através da tentativa de confrontar o passado sem se inscrever num régime de verdade que procura fixar a memória a partir de certos parâmetros. Uma memória oficial que, como argumenta Michel Foucault, estabelece as fronteiras entre o "certo" e o "errado", sendo que o segundo termo está tradicionalmente ligado às práticas que simultaneamente ameaçam e reiteram a ordem social, legitimando a implementação de políticas disciplinares (Foucault, 2000, p. 47-48). No caso específico dos discursos sobre a ditadura militar, isso significa problematizar uma dupla vertente que tem dominado os debates sobre a ditadura: a versão dos militares e a da esquerda militante. A necessidade de trazer novas possibilidades de leitura do passado decorre do fato de que:

nem todo mundo compartilha das mesmas memórias. Há narrativas conflitantes baseadas em confrontos ideológicos. Mais do que isso, há divisões entre aqueles que experimentaram a repressão ou a guerra em diferentes estágios de suas vidas... Essa multiplicidade de memórias e narrativas do passado gera uma dinâmica particular na circulação social das memórias (Jelin, 2003, p. 37, tradução nossa).

Essa perspectiva deve ser complementada pelo fato de que, se a memória funciona como um marco na criação de um senso de pertencimento, é preciso lançar um olhar crítico sobre seu processo de criação e legitimização, uma vez que "para estabelecer os parâmetros identitários (nacional, de gênero, político ou de qualquer outro tipo), o sujeito seletivamente toma certas marcas, certas memórias que o localizam em relação ao "outro'" (Jelin, 2003, p. 14, tradução nossa). O problema é que certas perspectivas tentam se impor como as "verdadeiras" e isso gera tensões. Por outro lado, deve-se ter em mente que a simples compilação de dados não deve ser confundida com a memória da ditadura, uma vez que "a memória excede em muito qualquer relato factual, não importando a importância que o último venha a ter como um passo para o processo político e jurídico inicial" (Avelar, 2004, p. 64, 
tradução nossa). ${ }^{6}$ Avelar argumenta que "a literatura testemunhal deixou um legado muito escasso para a reinvenção da memória depois das ditaduras [...]. Em outras palavras, o pior desserviço crítico que se pode fazer a esses textos, à verdade que eles contêm - factual - é tratálos como muita crítica testemunhal tem feito: como guias históricos de alguma revolução que finalmente permitiu que o subalterno falasse livremente" (Avelar, 2004, p. 64, tradução nossa).

A tentativa de problematizar essa prática no filme não se restringe tão somente às estratégias até aqui discutidas, mas o ato de montar e desmontar os fragmentos da memória a partir da experiência de mulheres envolvidas com o movimento de resistência permite ampliar o espaço do dizível. Nesse contexto, as mulheres deixam de ser simplesmente "repositórios conservadores do arcaico nacional" e ganham livre-arbítrio no processo de transformação da nação (McClintock, 1997, p. 93, tradução nossa). ${ }^{7}$ Trata-se, por conseguinte, de uma proposta que procura interromper e contestar uma pedagogia nacionalista que legitima "uma visão homogênica e horizontal [e eu acrescentaria gendrada] associada com a comunidade imaginada da nação" (Bhabha, 2002, p. 144, tradução nossa). Depara-se, em última instância, com um rememorar em que as mulheres deixam de ser receptoras passivas e passam a ser vistas como agentes ativamente envolvidos no processo de elaboração de significados. Isso explica a necessidade de restaurar diversas formas de copresença que permitam a construção de quadros menos excludentes da memória. Pode-se mesmo dizer que a ênfase na instabilidade dos significados que se pode atribuir às experiências do passado realça a tensa dicotomia entre memória e esquecimento, remetendo para uma série de questionamentos sobre o processo de seleção e legitimação de certos quadros sociais da memória.

\footnotetext{
${ }^{6}$ Um exemplo é o livro Brasil: nunca mais, que, organizado pela Arquidiocese de São Paulo, reúne cópias de mais de 700 processos judiciais e relatos sobre a tortura e os desaparecidos durante a ditadura militar.

${ }^{7}$ Nira Yuval-Davis e Floya Anthias, por exemplo, designam cinco maneiras pelas quais as mulheres estão intimamente associadas ao nacionalismo: como reprodutoras biológicas, como reprodutoras de suas fronteiras étnicas e nacionais, como reprodutoras da coletividade e transmissoras da cultura, os significantes simbólicos da diferença nacional e, por último, como participantes das lutas nacionais (Yuval Davis e Anthias, 1989, p. 7). Essa percepção aponta para o caráter gendrado das nações, percebido nos "sistemas de representação cultural que limitam e legitimam o acesso das pessoas aos recursos do Estado-nação” (McClintock, 1997, p. 89).
} 
A busca por uma nova linguagem para falar do passado também traz um novo ingrediente através da relação que se estabelece entre passado e presente. $\mathrm{Na}$ realidade, a pergunta que orienta o filme ("Como sobrevivemos?") já aponta para a preocupação em interligar a experiência do presente à do passado. Um exemplo seria a correlação que se estabelece entre duas situações limítrofes, como são os casos de Regina Toscano e de Maria Luiza G. Rosa. Trabalhando com comunidades marginalizadas na Baixada Fluminense, Regina e Maria Luiza estão envolvidas com organizações de mulheres. Maria Luiza, por exemplo, faz uma correlação entre a violência da tortura e as diferentes formas de violência que fazem parte do dia a dia de muitos moradores da Baixada Fluminense. $O$ desafio aqui reside em combater uma violência sistêmica que se traduz na falta de investimento em infraestrutura e serviços ou na ausência de políticas que poderiam propiciar uma melhor qualidade de vida para os moradores. ${ }^{8} \mathrm{O}$ que se percebe nesse caso é que, ao entrelaçar a memória da ditadura a outras formas de violência, o filme obriga a audiência a pensar criticamente não só sobre o processo de construção da memória coletiva, mas também sobre os efeitos que a ditadura tem no momento presente. Tanto é assim que as únicas pessoas que não se sentem intimidadas ou perplexas ante o relato das torturas são os moradores da Baixada Fluminense, uma vez que, como Maria Luiza afirma, há certa identidade entre os dois grupos. Identidade essa construída a partir de certo amortecimento perante uma realidade violenta e sem sentido.

A verdade é que, ao entrelaçar as experiências do passado e do presente, mostrando a forma como a violência é parte intrínseca da estrutura social brasileira, o filme aponta para uma realidade extremamente complexa que não pode ser abarcada por uma lógica simplista e maniqueísta que se constitui a partir de categorias como "inimigo", "vítima", "resistência democrática" ou "o bem do povo". 9 Ao dar ênfase ao dia a dia dessas mulheres em sua constante luta por

\footnotetext{
${ }^{8}$ De acordo com Slavoj Žižek, o foco sobre a violência subjetiva (violência promulgada pelos atores sociais) distrai a nossa atenção do verdadeiro núcleo de violência e, consequentemente, contribui para a reprodução do sistema, que permite que isso aconteça no primeiro lugar (Žižek, 2008, p. 9). Isso significa dizer que, quando a violência é percebida como circunscrita a um ato ou indivíduo, as suas dimensões socioeconômicas são obscurecidas ou se tornam invisíveis.

${ }^{9}$ Uma prática que não está restrita ao Brasil, como advertem estudiosos como Idelber Avelar (1999) e Nelly Richard (2000).
} 
encontrar um equilíbrio que lhes permita continuar vivendo, o filme procura "combater uma ideia romântica da guerrilha", como tão bem coloca Criméia. Isso nos ajuda a entender a forma algumas vezes agressiva com que a personagem de Irene Ravache se dirige à audiência. Em um determinado momento, por exemplo, a personagem reivindica seu direito a retomar a posse sobre o seu corpo ao argumentar em tom desafiador: "Eu gosto de trepar. Por que eu não tenho o direito de gostar? Porque marcaram o meu corpo? Não marcaram, não. É só lavar". Ou mesmo quando questiona a forma como tradicionalmente se constroem os relatos sobre a tortura: "A tortura só pode ser descrita. Passou três dias no pau-de-arara. Ficou paralítica. Levou choque generalizado pelo corpo. Assim, rápido, curto, grosso, impessoal. Mas ninguém fez xixi no pau-de-arara, ninguém caiu do pau-de-arara, ninguém riu de ninguém". Tal como nos depoimentos ou nas fotografias, essas intervenções procuram desestabilizar uma narrativa que procurou (e em muitos casos ainda procura) construir uma imagem épica do movimento de resistência à ditadura.

Logo, se algo marca esse ato de rememorar, é a presença de uma fala que oscila entre as esferas individual e coletiva na tentativa de ressemantizar o passado. Por essa razão, apesar de o filme trazer o choro, o medo, as contradições e o sentimento de culpa que são parte do dia a dia das ex-prisioneiras políticas, a audiência também compartilha dos momentos de alegria e das novas lutas. Em nenhum momento há a intenção de transformá-las em símbolos ou vítimas de uma resistência heroica em nome da democracia. Muito pelo contrário, depara-se com um rememorar que procura levar a audiência a questionar não só a violência do regime militar mas também o posicionamento da esquerda ao censurar ou expulsar de seus quadros os membros que, em meio à tortura, passaram informação para os torturadores. Da mesma forma, a correlação que se estabelece entre a vivência dessas mulheres ontem e hoje e o cotidiano de comunidades marginalizadas permite desnudar as mais diferentes formas de violência e seu impacto sobre os indivíduos. Não é por acaso que uma das epígrafes no início do filme, citando o psicanalista Bruno Bettelheim, informa: "A psicanálise explica por que se enlouquece, não por que se sobrevive". É basicamente a resposta a essa pergunta que o filme tenta traçar. No entanto, para alcançar tal objetivo, a sintaxe oficial precisa ser deslocada do relato frio dos arquivos ou da retórica heroica da esquerda e trazida para a dimensão 
dos indivíduos. O resultado é a presença de uma linguagem que coloca em circulação uma diversidade de verdades e silêncios, obrigando sua audiência a questionar o próprio processo de institucionalização da história - um passo crucial se quisermos um futuro diferente, como tão bem alerta Paulo Freire.

\section{Referências}

AVELAR, Idelber (1999). The untimely present: postdictatorial Latin American fiction and the task of mourning. Durham: Duke University Press.

(2004). The letter of violence: essays on narrative, ethics, and politics. New York: Palgrave Macmillan.

ARQUIDIOCESE DE SÃO PAULO (1985). Brasil: nunca mais. Petrópolis: Vozes.

BAFFA, Ayrton (1989). Nos porões do SNI: o retrato do monstro de cabeça oca. Rio de Janeiro: Objetiva.

BHABHA, Homi (2002). DissemiNation: time, narrative, and the margins of the modern nation. In: The location of culture. London: Routledge.

DIAS, Reginaldo Benedito (2013). A Comissão Nacional da Verdade, a disputa da memória sobre o período da ditadura e o tempo presente. Patrimônio $e$ memória, São Paulo, v. 9, n. 1, p. 71-95.

FREIRE, Paulo (2002). Pedagogia do oprimido. 18. ed. São Paulo: Paz e Terra.

FOUCAULT, Michel (2000). Power. Essential works of Foucaut 1954-1984. v. 3. Edição de J. D. Faubion. New York: New Press.

HAAKEN, Janice (1998). Pillar of salt: gender, memory, and the perils of looking back. Brunswick: Rutgers.

HALBWACHS, Maurice (1992). On collective memory. Chicago: University of Chicago Press.

HALL, Stuart (1995). The question of cultural identity. In: HALL, Stuart et al. (ed.). Modernity: an introduction to modern societies. Cambridge: Polity Press.

HOBSBAWM, Eric (1994). Age of extremes: the short twentieth century, 19141991. London: Michael Joseph.

JELIN, Elizabeth (2003). State repression and the labors of memory. Minneapolis: University of Minnesota Press. 
MCCLINTOCK, Anne (1997). No longer in a future haven: gender, race, and nationalism. In: MCCLINTOCK, Anne; MUFTI, Aamir; SHOHAT, Ella (Eds.). Dangerous liaisons: gender, nation, and postcolonial perspectives. Minneapolis: University of Minnesota Press.

OLICK, Jeffrey K. (1998). What does it mean to normalize the past? Official memory in German politics since 1989. Social science history, Beverly Hills, v. 22, n. 4 , p. 547-571.

QUE BOM te ver viva (1989). Direção e produção de Lúcia Murat. Rio de Janeiro: Taigá Filmes \& Vídeos. 1 Videocassete (100 min.).

RICHARD, Nelly (Ed.) (2000). Políticas y estéticas de la memória. Santiago: Cuarto Propio.

STEPAN, Alfred (1976). The new professionalism of internal warfare and military role expansion. In: Authoritarian Brazil: origins, policies, and future. New Haven: Yale University Press.

YUVAL-DAVIS, Nira (1997). Gender \& nation. London: Sage.

; ANTHIAS, Floya (1989). Introduction. In: YUVAL-DAVIS, Nira; ANTHIAS, Floya; CAMPLING, Jo (Eds.). Women-nation-state. Basingstoke: Macmillan.

ŽIŽEK, Slavoj (2008). Violence. London: Profile.

Recebido em dezembro de 2013.

Aprovado em fevereiro de 2014.

\section{resumolabstract}

\section{Que bom te ver viva: vozes femininas reivindicando uma outra história}

Kátia da Costa Bezerra

O direito de determinar o significado da ditadura militar no Brasil tem sido o centro de uma polêmica envolvendo membros da esquerda militante e do regime militar. A linguagem usada pelos dois grupos constantemente se revolve em torno de imagens míticas de "heróis", "vítimas" ou "para o bem do povo". Este ensaio discute o filme Que bom te ver viva, de Lúcia Murat, que traz uma nova perspectiva para esse debate. Tendo como ponto de partida o testemunho de oito ex-prisioneiras políticas, o filme procura responder a pergunta "Como sobrevivemos?". O ensaio discute como o filme constrói quadros de memória que vão além daqueles tidos como representativos. 
Palavras-chave: ditadura militar, mulheres, violência, livre-arbítrio, tortura, memoria.

\section{Que bom te ver viva: female voices demanding another history}

Kátia da Costa Bezerra

The right to determine the meaning of the military dictatorship in Brazil has been a constant dispute between members of the militant left and the military regime. The language used by the two groups constantly revolves around the mythic images of "heroes", "victims", "for the good of the people". This essay focuses on Que bom te ver viva, by Lúcia Murat, who brings a new perspective to this debate. Taking as a point of departure the testimony of eight ex-political prisoners, the film attempts to answer the question: How did we survive?" The essay discusses how the movie builds frames of memory that go beyond those taken as representative.

Keywords: military dictatorship, women, violence, agency, torture, memory. 